\title{
Host Reactions in Young Birds to Naturally Occurring Superinfestations with Porrocaecum ensicaudatum
}

\author{
By Jean G. Baer, F.M.L.S. \\ Institut de Zoologie, Université de Neuchâtel
}

The young of all nest dwelling birds are fed continuously by their parents. It is the latter therefore who choose the food which is mostly composed of that which the adult birds feed on. Under these circumstances it is therefore not surprising that fledglings when still in the nest are found to harbour helminths of which the larval forms were contained in the food*.

It is possible, at times, to find enormous numbers of worms in young nestlings whereas the adult birds only harbour one or two specimens. We have reported (1956) having found the crop of young Fulmars taken on the nest to contain hundreds of specimens of Stegophorus stellae-polaris (Parona) whereas this species is not very common in adult birds. It seems that such cases must not be uncommon but usually escape the notice of helminthologists working in the field; nor has the mechanism by which young birds rid themselves of such an excess of parasites been given any particular attention. For helminths that migrate at one stage or another through the host's tissues, it seems plausible that some sort of immunological reaction arises.

It is for this reason that we think it might be interesting to report a series of observations made throughout the year on a population of blackbirds that feeds in the immediate vicinity of our Institute. We have previously reported (1960) the presence of Euamphimerus pancreaticus Baer in the pancreatic ducts of these birds and have drawn attention to the fact that the parent birds feed their young on very small fishes, which would account for the source of this infestation. Unfortunately further work on this subject has been handicapped by bad meteorological conditions and an epizootic amongst the fishes of the lake of Neuchâtel.

* An exception to this rule is found in young cuckoos which apparently never harbour their foster-parents' tapeworms. 
Of the sixty blackbirds that were examined for parasites, about 25\% were infested with the ascarid Porrocaecum ensicaudatum (Zeder, 1800). Heavy infestations with adult worms were rare except in a single case of a young bird from this year's first brood, shot on May 16th, 1960. Not only did the gut contain more than one hundred adult worms, but all stages of development were found within the intestinal mucosa.

Several years previously while examining earthworms (Allolobophora chlorotica Sav.) collected in a nearby wood we found, in loam covered with blackbird droppings, one particular population of earthworms which was heavily parasitized by larval nematodes occurring within the ventral blood vessel. About $60 \%$ of the earthworms were parasitized. When fed to young blackbirds and to ducklings, the nematode larvae were found within $\mathbf{4 8}$ hours beneath the horny layer of the gizzard. Unfortunately this experiment could not be continued.

Osche (1955) has recently described the third larval stage of Porrocaecum ensicaudatum from the ventral blood vessel of Lumbricus herculeus Sav. from Erlangen (Germany). His very accurate description draws attention to the fact that the gut of these larvae is filled with blood and that the intestinal cells are densely packed with fine, dark brown granules which appear to be derived from digested blood. The whole gut is distinctly visible on this account especially when the earthworm is examined by transmitted light (Fig. 1). On all sections of the third larval stage the intestinal cells are densely black (Figs. 2 and 3).

The third larval moult appears after the larvae have burrowed beneath the horny layer of the gizzard (Fig. 4) and it is usually assumed that the fourth stage larvae pass into the gut lumen and later become adult.

On several occasions we have found such fourth stage larvae measuring about $10-11 \mathrm{~mm}$. in length and recognizable by the remains of digested blood within the intestinal epithelium, at different levels of the intestine within the mucosa. Usually, the anterior extremity of the larva pierces the surface of the mucosa and the entire worm may be easily removed with fine forceps. A section passing through such a larva in situ (Fig. 5) distinctly shows the pigment granules in the gut wall which are responsible for the black, hair-like thread that appears against the pink background of the 
bird's intestine. The section also shows the presence of a distinct host reaction surrounding the larva and consisting chiefly of leucocytes and eosinophilic cells. This reaction probably accounts for the ease with which the larvae can be removed from the mucosa.

The question arises as to whether the presence of the fourth larval stage within the intestinal mucosa of the host is a normal phase of the life cycle or whether it represents a reaction of the host to successive infestations. We are inclined to adopt the latter alternative in view of our findings in the young blackbird, mentioned above, in which fibrous tumours occurred on the peritoneal surface of the intestine. The presence of such tumours has never been recorded in any of our blackbirds, either in adult or in young birds. Nor have we ever come across a bird so heavily infested as that described in this paper.

We have been fortunate in finding in our sectioned material evidence of that which we interpret as being the cause of these tumours, namely, a host reaction against an exceptionally heavy infestation with larval worms.

When a section of a tumour is examined under the microscope, the centre is formed by a cavity, whose walls are lined by a syncytium of giant cells; outside this lies the fibrous connective tissue reaction (Fig. 7). Within the cavity the fifth larval stage is found, partly surrounded by the fourth moult. This reaction occurs every time that a fourth stage larva moults within the mucosa and it might quite possibly be elicited by a direct effect of the moulting fluid on the host's tissues, judging from the purely localized reaction. In Fig. 6 is seen an early stage of this process and in Fig. 8 the ultimate stage where the worm has been destroyed and the tissues are beginning to be restored.

There seems to be no doubt whatever that we are dealing here with a self-defence reaction of a host towards a series of successive infestations with larvae of $P$. ensicaudatum. An indication that some form of an immunological reaction of a more general type also occurs, is found in the presence of the fourth larval stages within the mucosa all along the intestine and the fact that these larvae moult while still in the tissues of the host. There thus appears to exist a general inhibitory mechanism affecting normal larval development that finally leads to the destruction by phagocytes of the fifth larval instars. 
This kind of defensive reaction in a normal host does not seem to have been described before but probably only occurs in young birds that have been heavily infested by their parents. It shows how a juvenile host is able to rid itself of an excess of worms even though it does so at some expense to its organism. The young blackbird mentioned above was looking very sorry for itself, its feathers were ruffled and it had trouble keeping its balance when hopping on the ground.

\section{REFERENCES}

BAER, JeAN G., 1956.-."Parasitic helminths collected in West Greenland." Medd. Grenland, 124, 55 pp. (W.L. 12862).

1960.- - Une nouvelle espèce de Trématode, Euamphimerus pancreaticus n.sp. (Opisthorchiidae)." Bull. Soc. neuchâtel. Sc. nat., 83, 63-70. (W.L. 5299).

Osche, G., 1955.-“"Ueber Entwicklung, $Z$ wischenwirt und Bau von Porrocaecum talpae, Porrocaecum ensicaudatum und Habronema mansioni (Nematoda)." Z. Parasitenk., 17, 144-164. (W.L. 23536b). 

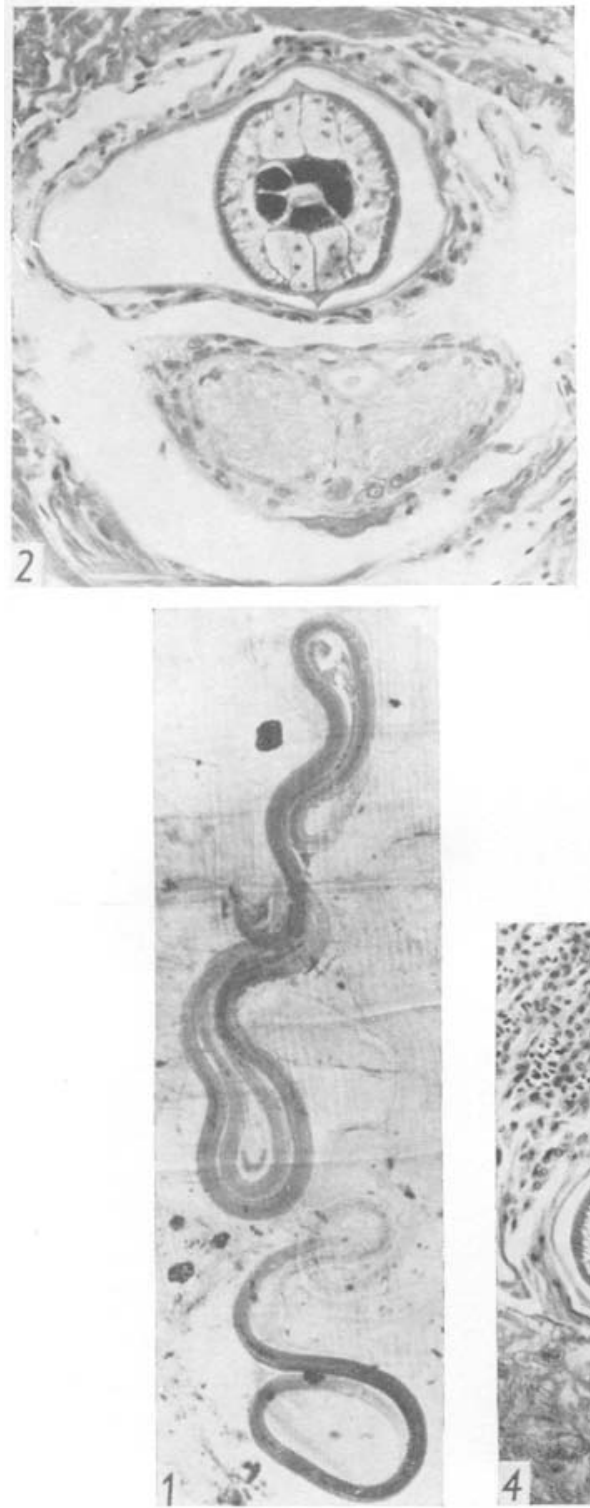
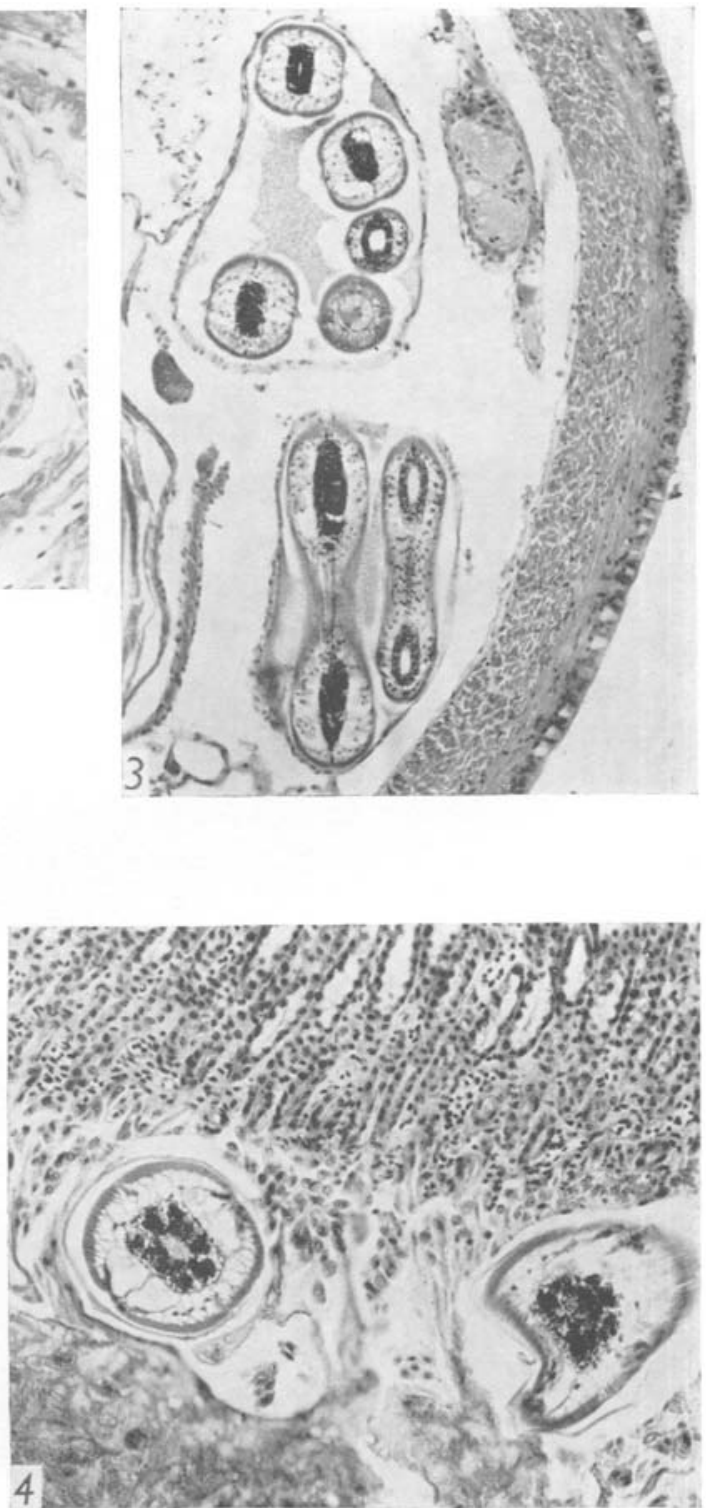

Fig. 1.-Earthworm with gut removed, showing the third larval stage $(P$. ensicaudatum) inside the ventral blood vessel. Fig. 2.-Transverse section of an earthworm showing a larva with intestinal cells densily packed with pigment granules lying within the ventral vessel immediately above the longitudinal nerve chain. Fig. 3. - Transverse section of an earthworm showing several larvae coiled within the ventral vessel. Fig. 4.-Section of the gizzard wall of a young blackbird infected experimentally 48 hours previously with earthworms. The horny layer is visible in the bottom left hand corner and the third moult is clearly seen surrounding the fourth larval stage. 

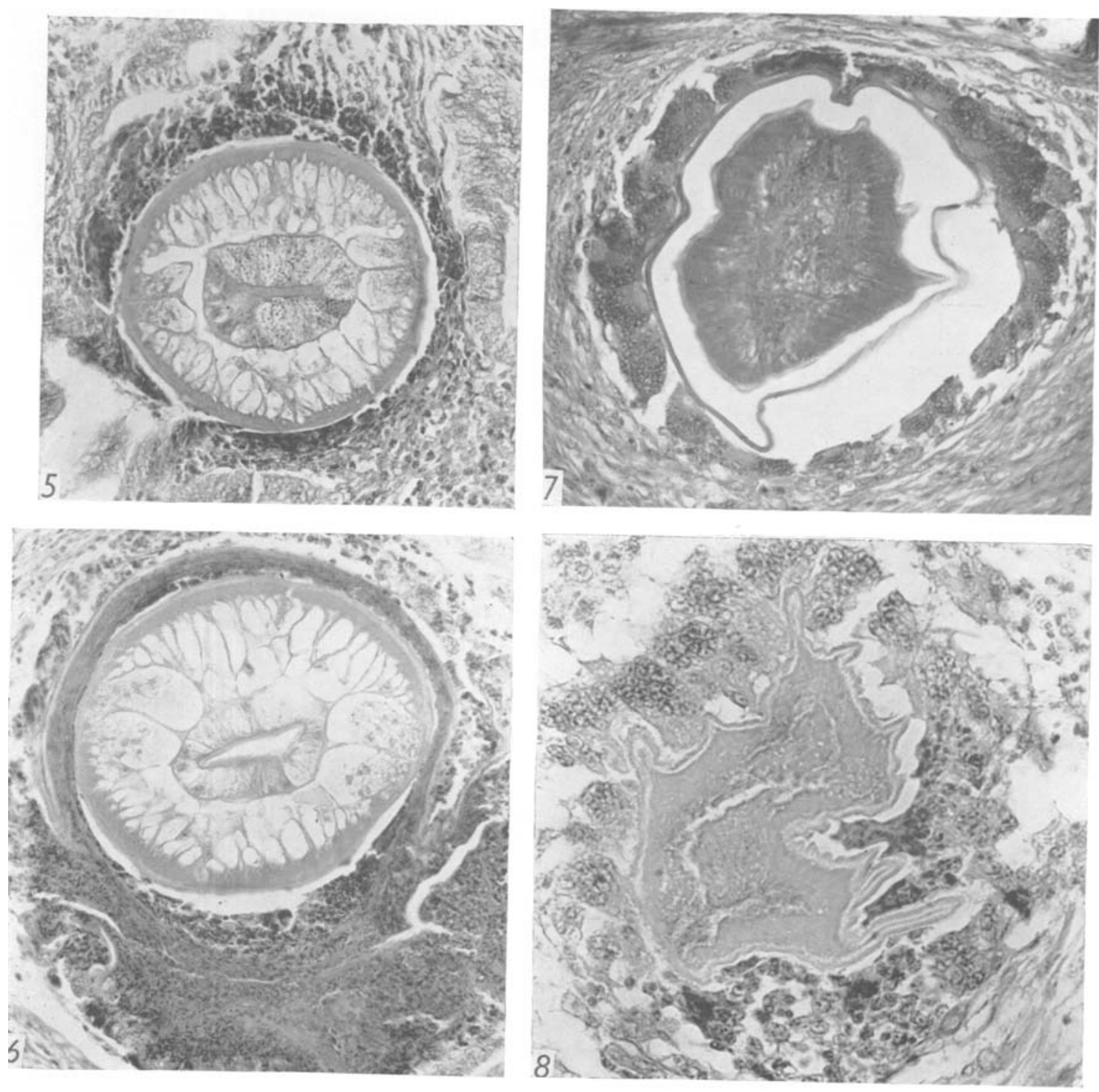

Fig. 5.- Section of a fourth stage larva $(P$. ensicaudatum $)$ within the intestinal mucosa of the host. The pigment granules within the gut cells of the larva are much less numerous and a mild host reaction is seen around the larva. Fig. 6.Section of a fifth stage larva within the intestinal mucosa of the host. The fourth moult is visible in the upper part of the section and a violent host reaction with giant cell formation in the lower part. Fig. 7.- Section of a tumour in the centre of which is a fifth stage larva surrounded by a syncytium of giant cells. Fig. 8.- Section through an ultimate stage where the nematode has been destroyed by the host reaction. Several giant cells are still visible as well as the "loosening up" of the fibrous structure of the tumour. 